\title{
Screening of Xanthine Oxidase Producing Microorganisms Using Nitroblue Tetrazolium Based Colorimetric Assay Method
}

\author{
Amit Agarwal and U.C. Banerjee* \\ Department of Pharmaceutical Technology (Biotechnology), National Institute of Pharmaceutical Education and Re- \\ search, Sec-67, SAS Nagar-160067, Punjab, India
}

\begin{abstract}
Xanthine oxidase is a highly versatile and ubiquitous complex molybdoflavoprotein, which controls the rate limiting step of purine catabolism pathway. Microbial xanthine oxidase can be used to address a number of questions presently not feasible with the eukaryotic enzymes. In the present study, a high-throughput microtitre plate-based colorimetric assay for xanthine oxidase producing microorganism was developed. Superoxides produced by microbial cultures, grown on xanthine rich medium interacts with nitroblue tetrazolium (NBT) solution and produces dark blue color, which facilitates the rapid screening of xanthine oxidase producing microorganisms and could be adapted for quick quantitative assessment and distribution of xanthine oxidase in many heterogeneous microbial communities. The method developed may be utilized for the rapid screening of a variety of xanthine oxidase producing microorganisms from the nature.
\end{abstract}

Key Words: Xanthine, nitroblue tetrazolium, allopurinol, screening, microbial xanthine oxidase.

\section{INTRODUCTION}

Xanthine oxidase is a highly versatile and ubiquitous complex molybdopterin, first identified a century ago in milk [1]. Most of the xanthine metabolizing organisms possess a molybdopterin cofactor-containing enzyme that oxidizes xanthine to uric acid and transfers electrons to $\mathrm{NAD}^{+}$(xanthine dehydrogenase) or oxygen (xanthine oxidase) [2]. Although mammalian xanthine oxidase exists originally as a dehydrogenase form, but it can be easily converted to oxidase form either irreversibly [3], or reversibly [3-5]. These different forms of xanthine oxidoreductases are generally conserved in living organisms, including archaea, bacteria, fungi, plants, and metazoans [6] and it has been revealed from different sources that these isoforms are all fundamentally similar with regard to molecular properties, prosthetic group content and substrate specificity [7]. Xanthine oxidase is capable of oxidizing varieties of purines and related compounds and physiologically participates in a variety of biochemical reactions including hydroxylation of various purines, pterines and aromatic heterocycles, as well as aliphatic and aromatic aldehydes and hence plays a significant role in the detoxification or activation of endogenous compounds and xenobiotics [8].

The standard spectrophotometric assay of xanthine oxidase is based on the oxidation of xanthine/hypoxanthine to uric acid [9]; in case of microbial xanthine oxidase assay, it suffers from the drawback of being slow and less sensitive. There is a pressing need to develop high throughput assays,

*Address correspondence to this author at the Department of Pharmaceutical Technology (Biotechnology), National Institute of Pharmaceutical Education and Research, Sec-67, SAS Nagar-160067, Punjab, India; Tel: +91172-2214682-87, Ext.2142; Fax: +91-172-2214692;

E-mail: ucbanerjee@niper.ac.in which would greatly facilitate work on xanthine oxidase/ xanthine dehydrogenase (and other enzymes), and specifically would potentiate the use of combinatorial chemical libraries to screen for novel lead compounds (antigout, antimicrobial, antitumor). We made an attempt to develop microbial xanthine oxidase assay based on the reactivity of superoxides produced during the course of the reaction. The aerobic oxidation of xanthine/hypoxanthine by xanthine oxidase is associated with the formation of hydrogen peroxide and superoxides [10]. This has prompted us to use the xanthine oxidase system with xanthine/hypoxanthine as substrate as a model of the high throughput screening of microbial xanthine oxidase. The underlying principle [11] was used to develop the colorimetric assay for screening of xanthine oxidase producing microorganisms from the soil sample.

Xanthine $+\mathrm{O}_{2} \longrightarrow \begin{aligned} & \text { Uric acid }+ \\ & \text { Superoxides }\end{aligned} \stackrel{\text { NBT (yellow) }}{\longrightarrow} \begin{aligned} & \text { Formazan } \\ & \text { (dark blue) }\end{aligned}$

\section{MATERIALS AND METHODS}

Xanthine, allopurinol, xanthine oxidase (from bovine milk; grade II), were purchased from Sigma- Aldrich Inc., USA. Nitroblue tetrazolium and all other chemicals were obtained from Hi-media Inc. Mumbai, India.

\section{Microbial Culture}

A $2 \times 2 \mathrm{ft}$. area in the institute's garden was selected for the primary enrichment of xanthine utilizing microorganisms in the soil. A solution of xanthine $\left(2 \mathrm{mmol} \mathrm{l}^{-1}\right)$ was sprayed on the designated soil at a regular time interval and samples were collected from it. This process of spraying of xanthine and collecting soil samples continued for 4-6 months. A soil suspension was prepared by adding $10 \mathrm{ml}$ tap water to $1 \mathrm{~g}$ 
soil sample. It was vortexed and $1 \mathrm{ml}$ supernatant was used as an inoculum in $100 \mathrm{ml}$ minimal salt medium (MSM) containing xanthine $\left(2 \mathrm{mmol} \mathrm{l} \mathrm{I}^{-1}\right)$ and incubated at $30{ }^{\circ} \mathrm{C}$ in an orbital shaker (200 rpm) for $4-6$ days. Enriched samples were streaked on selective plates (containing xanthine) in MSM agar. Positive isolates were selected on the basis of growth on the selective plates and organisms obtained in this waywere purified and maintained on nutrient agar plates $(0.5 \%$ peptone, $0.15 \%$ yeast extract, $0.5 \%$ beef extract. $0.5 \%$ sodium chloride, agar $1.5 \%, \mathrm{pH} 7.6)$.

\section{Detection of Microbial Xanthine Oxidase Using the Ni- troblue Tetrazolium Based Assay}

This method was developed by modifying the polyacrylamide gel activity staining method used by Ozer et al. [11] for xanthine oxidase. Microbial culture, grown on xanthine as a sole source of carbon and nitrogen; was centrifuged and the pellet was suspended in Tris- $\mathrm{HCl}$ buffer $\left(50 \mathrm{mmol}^{-1}, \mathrm{pH}\right.$ 7.6). Each reaction contained $150 \mu \mathrm{l}$ microbial cell (concentration varied from 25 to $150 \mathrm{mg} / \mathrm{ml}$ ), lysed with $\mathrm{NaOH}$ $\left(1 \mathrm{~mol} \mathrm{l}^{-1}\right)$; $150 \mu \mathrm{l} \mathrm{NBT}$ solution containing $50 \mathrm{mmol}^{-1}$ Tris$\mathrm{HCl}, \mathrm{pH} 7.6,2 \mathrm{mmol}^{-1}$ xanthine and $0.50 \mathrm{mmol}^{-1}$ nitroblue tetrazolium. The reaction mixture was incubated for $5 \mathrm{~min}-$ utes at ambient temperature, centrifuged and absorbance of supernatant was measured by microplate readers (Emax, Molecular Devices, California) at $575 \mathrm{~nm}$. This was used a test sample. Three control experiments were set with this assay. First control consists of $150 \mu \mathrm{l}$ NBT solution and 150 $\mu \mathrm{NaOH}\left(1 \mathrm{~mol} \mathrm{l}^{-1}\right)$ which is termed as negative control. This was carried out to see the interaction between NBT and xanthine in alkaline conditions. Second control experiment was set in which $150 \mu \mathrm{l}$ microbial culture was incubated with allopurinol (50 $\mathrm{mmol} \mathrm{l}^{-1}$ ) for 5 minutes at ambient temperature and to this mixture, $150 \mu \mathrm{l}$ NBT solution was added and again incubated for 5 minutes at ambient temperature, centrifuged and absorbance of the supernatant was measured by microplate readers (Emax, Molecular Devices, California) at $575 \mathrm{~nm}$. This control experiment determined the superoxides formed by the action of enzymes other than xanthine oxidase present in the microbial cultures. The third control experiment is the positive control which was set up with commercially available xanthine oxidase (0.02 units) from bovine milk (grade II), keeping all the reaction parameters same.

\section{RESULTS}

A large number of microorganisms exhibits xanthine dehydrogenase/xanthine oxidase activity [7, 12], and, in some cases, enzyme activity can be induced by growing the microorganism in a medium with xanthine/hypoxanthine as sole carbon and nitrogen source. Microbial cultures which showed positive growth on the nutrient agar plates, containing xanthine as a sole source of carbon and nitrogen; reacts with NBT solution and give dark blue color. As assumed, no color was developed in the negative control (Fig. 1), while

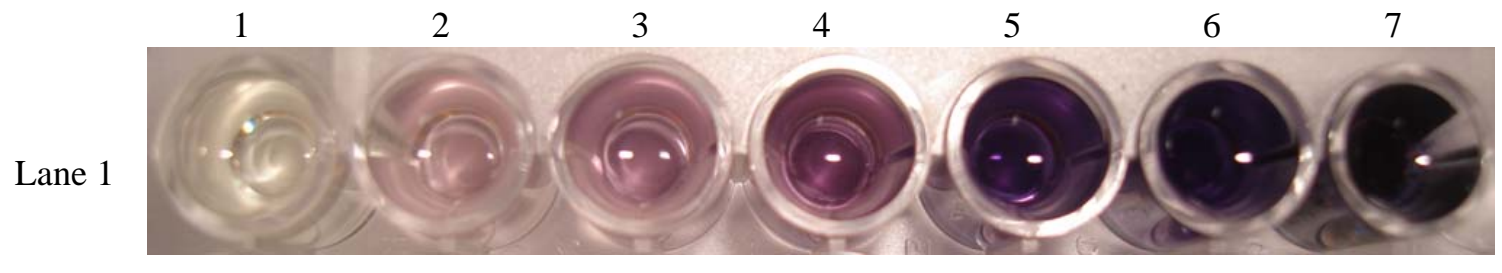

Lane 2

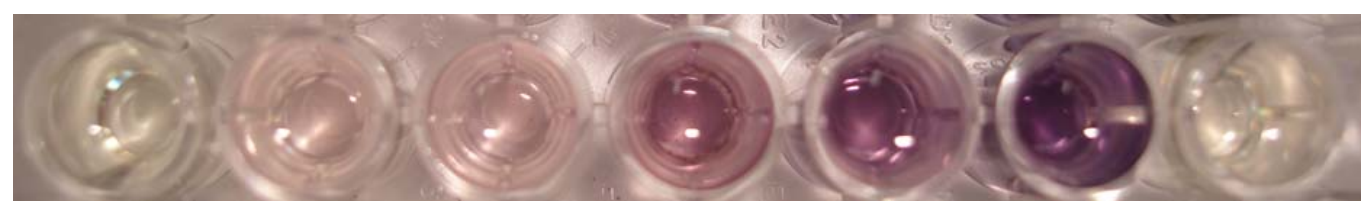

Lane 3

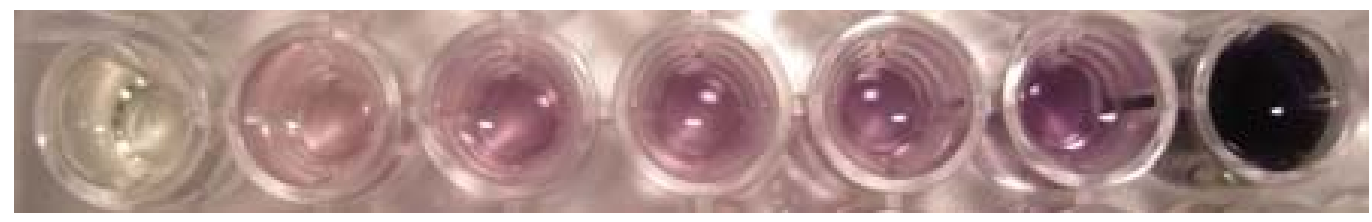

Lane 4

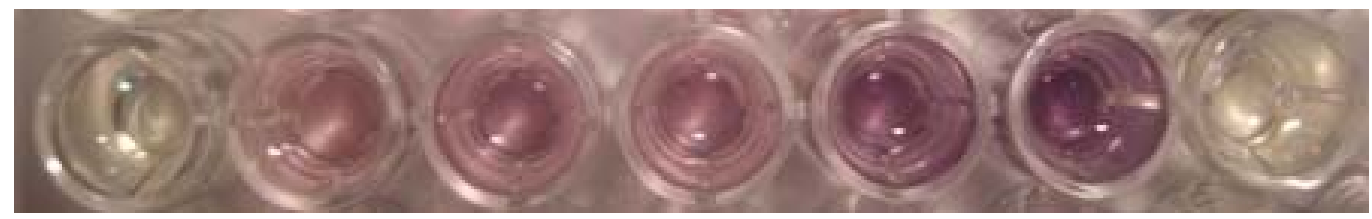

Fig. (1). Microtitre plate-based colorimetric assay of xanthine oxidase producing microorganisms.

Lane 1, Showing the blue colour of formazan formed due to the interaction of the super oxides with NBT. well 1: negative control, well 2: 25 $\mathrm{mg} / \mathrm{ml}$, well 3: $50 \mathrm{mg} / \mathrm{ml}$, well 4: $75 \mathrm{mg} / \mathrm{ml}$, well 5: $100 \mathrm{mg} / \mathrm{ml}$, well 6: $150 \mathrm{mg} / \mathrm{ml}$ cell mass well 7: xanthine oxidase from bovine milk, grade II (0.02 units), as positive control; Lane 2, Showing the same reactions in the presence of allopurinol $\left(50 \mathrm{mmol}^{-1}\right)$, standard inhibitor of xanthine oxidase. Lane 3-4, Showing the microorganisms not having xanthine oxidase as no effect of allopurinol is appearing on enzyme activity. 
the microbial cultures which were treated with allopurinol; standard inhibitor of xanthine oxidase, showed the formation of light blue colour (Fig. 1) and the corresponding decrease in absorbance (Fig. 2A). In case of microorganisms, lacking xanthine oxidase activity there is almost no or negligible difference in the absorbance of the sample without allopurinol and the sample containing allopurinol (Fig. 2B). Ten strains were screened for xanthine oxidase activity and it has been observed that it varied from good to moderate to negligible amount (Table 1).

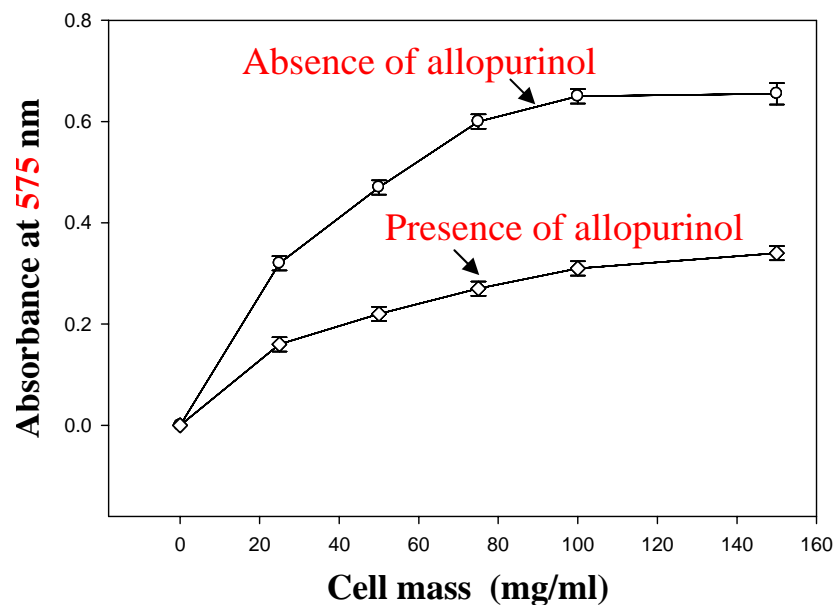

Fig. (2a). Oxidation of NBT by xanthine oxidase producing microorganisms in the absence and presence of allopurinol (All the reactions were replicated thrice with SEM \pm 0.10 and \pm 0.05 , respectively).

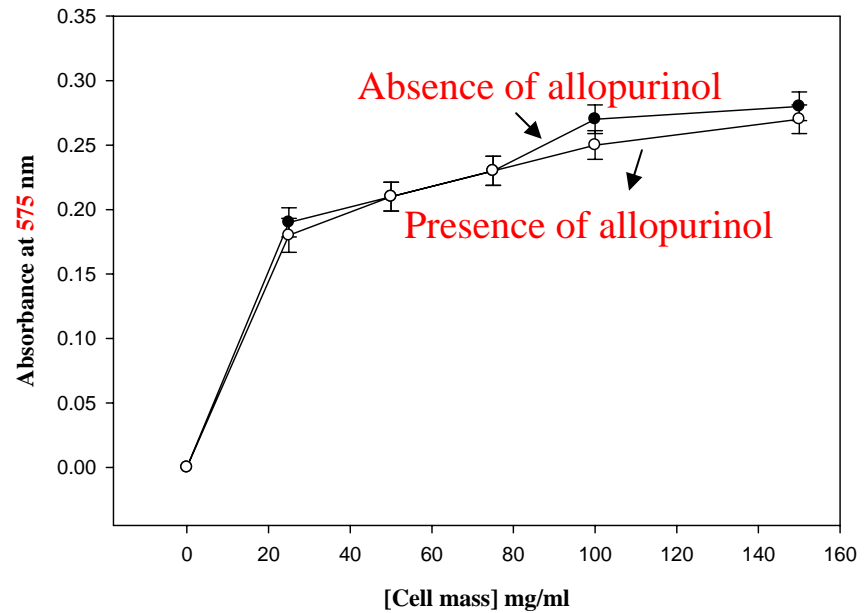

Fig. (2b). Oxidation of NBT by microorganisms deficient in xanthine oxidase activity in the absence and presence of allopurinol (All the reactions were replicated thrice with SEM \pm 0.13 and \pm 0.06 , respectively).

\section{DISCUSSION}

Dark blue color appears due to the formation of formazan, formed as a result of interaction of the NBT and superoxides produced during the course of the oxidation of xanthine to uric acid by xanthine oxidase. It is evident from Fig. (2A) that with the increase in the cell mass concentration, the increased absorbance indicats the increased amount of formazan formed due to the excess of superoxides produced during the reduction of the oxygen by microbial xanthine oxidase. However, when allopurinol was added to the reaction mixture, color intensity decreased due to the decrease in the production of superoxide radicals; as allopurinol inhibited the xanthine oxidase activity and hence free radical formation. Appearance of slight blue color can be attributed to the production of superoxides by other internal factors like mitochondrial electron chain and many autoxidation reactions. In case of microorganism lacking xanthine oxidase activity no change in color intensity has been observed in the absence and presence of allopurinol (Fig. 1), indicating that these microorganisms do not have the xanthine oxidase activity. In comparison to previous assays [13]; this assay system is simple and rapid for determining the xanthine oxidase activity in a large number of microorganisms. This high throughput colorimetric assay method can increase the efficiency of screening libraries of microorganisms for xanthine oxidase activity and also can be exploited for the screening of xanthine oxidase inhibitors.

Table 1. Xanthine Oxidase Activity Shown by Different Microorganism Grown on Xanthine Riched Medium

\begin{tabular}{|c|c|}
\hline Strain Number & Xanthine Oxidase Activity \\
\hline \hline 1 & ++ \\
\hline 2 & ++ \\
\hline 3 & + \\
\hline 4 & - \\
\hline 5 & ++ \\
\hline 6 & - \\
\hline 7 & ++ \\
\hline 8 & ++ \\
\hline 9 & + \\
\hline 10 & ++ \\
\hline
\end{tabular}

++ Good xanthine oxidase activity; + moderate xanthine oxidase activity; - no or negligible xanthine oxidase activity.

\section{CONCLUSION}

The xanthine oxidase/dehydrogenase system has been extensively studied with the bovine milk oxidase and chicken and rat dehydrogenase and has become the standards of comparison for xanthine oxidizing enzymes isolated from other sources [13, 14]. A more detailed understanding of the relative functional role of the redox cofactor (molybdopterin, two iron-sulfur centers, and FAD) found in these enzymes [4] will require the use of site-directed mutants and their characterization. Microbial xanthine oxidase can be exploited to address a number of questions presently not possible with the eukaryotic enzymes, such as (i) defects in the corresponding gene leading to hyperuricemia/gout, xanthinuria and various other related disorders; (ii) to know the functional roles of amino acid residues implicated in the catalytic 
mechanism of the enzyme (iii) to fully explore the complicated process of biosynthesis of functional form of the enzyme; (iv) to throw the light on the cofactor functional roles and electron transfer pathways in this oxidoreductase class of enzymes. These preliminary studies although precludes the detection of allozyme or isozyme multiplicity, but this assay method can pave a way in achieving the above mentioned tasks.

\section{ACKNOWLEDGEMENTS}

AA gratefully acknowledges the Department of Biotechnology, Government of India, for providing the junior research fellowship to carry out the work.

\section{REFERENCES}

[1] Schardinger F. Uber das Verhalten der Kuhmilch gegen Methylenblau und seine Verwendung zur Unterscheidung von ungekochter und gekochter Milch. Untersuch Nahrungs Genussmittel 1902; 5: 1113-21.

[2] Hille R. Molybdenum-containing hydroxylases. Arch Biochem Biophys 2005; 433: 107-16.

[3] Della CE, Stripe F. The regulation of rat lever xanthine oxidase: involvement of thiol groups in the conversion of the enzymatic activity from dehydrogenase into oxidase and purification of the enzyme. Biochem J 1972; 126: 739-45.

[4] Enroth C, Eger BT, Okamoto K, Nishino T, Nishino T, Pai EF. Crystal structure of bovine milk xanthine dehydrogenase and xan- thine oxidase: structure based mechanism of conversion. Biochemistry 2000; 97(20): 10723-28.

[5] Nishino T, Nishino T. The conversion from the dehydrogenase type to the oxidase type of rat liver xanthine dehydrogenase by modification of cysteine residues with fluorodinitrobenzene. J Biol Chem 1997; 272: 29859-64.

[6] Al-Khalidi UAS, Chaglassian TH. The species distribution of xanthine oxidase. Biochem J 1965; 97: 318-20.

[7] Woolfolk CA, Downard JS. Distribution of xanthine oxidase and xanthine dehydrogenase specificity types among bacteria. J Bacteriol 1977; 130(3): 1175-91.

[8] Borges F, Fernandes E, Roleira F. Progress towards the discovery of xanthine oxidase inhibitors. Curr Med Chem 2002; 9(2): 195-17.

[9] Takano Y, Haseaoki K, Horiuchi H, et al. Selectivity of febuxostat, a novel non-purine inhibitor of xanthine oxidase/xanthine dehydrogenase. Life Sci 2005; 76: 1835-47.

[10] Fridovich I. Quantitative aspects of the production of superoxides anion radical by milk xanthine oxidase. J Biol Chem 1970; 245(16): 4053-57.

[11] Ozer N, Oglu MM, Ogus IH. A simple and sensitive method for the activity staining of xanthine oxidase. J Biochem Biophys Methods 1998; 36: 95-100.

[12] Xiang Q, Edmondson DE. Purification and characterization of a prokaryotic xanthine dehydrogenase from Comamonas acidovorans. Biochemistry 1996; 35: 5441-50.

[13] Woolfolk CA, Downard JS. Bacterial xanthine oxidase from Arthrobacter S-2. J Bacteriol 1978; 135(2): 422-28.

[14] Sato A, Nishino T, Noda K, Amaya Y, Nishino T. The structure of chicken liver xanthine dehydrogenase cDNA cloning and the domain structure. J Biol Chem 1995; 270 (6): 2818-26.

(C) Agarwal and Banerjee; Licensee Bentham Open.

This is an open access article licensed under the terms of the Creative Commons Attribution Non-Commercial License (http://creativecommons.org/licenses/ by-nc/3.0/) which permits unrestricted, non-commercial use, distribution and reproduction in any medium, provided the work is properly cited. 